\title{
Clinical outcomes after treatment with direct-acting antivirals: not all concern hepatocellular carcinoma risk
}

\author{
Elton Dajti ${ }^{1}$, Federico Ravaioli ${ }^{1}$, Davide Festi ${ }^{1}$, Antonio Colecchia ${ }^{2}$ \\ ${ }^{1}$ Department of Medical and Surgical Sciences (DIMEC), University of Bologna, Bologna, Italy; ${ }^{2}$ Unit of Gastroenterology, Borgo Trento University \\ Hospital of Verona, Verona, Italy \\ Correspondence to: Antonio Colecchia. Unit of Gastroenterology, Borgo Trento University Hospital, 37126 Verona, Italy. Email: antonio.colecchia@aovr.veneto.it. \\ Provenance and Peer Review: This article was commissioned by the editorial office, Hepatobiliary Surgery and Nutrition. The article did not undergo \\ external peer review. \\ Comment on: Singal AG, Rich NE, Mehta N, et al. Direct-Acting Antiviral Therapy for Hepatitis C Virus Infection Is Associated With Increased \\ Survival in Patients With a History of Hepatocellular Carcinoma. Gastroenterology 2019;157:1253-1263.e2.
}

Submitted Nov 04, 2019. Accepted for publication Nov 30, 2019.

doi: 10.21037/hbsn.2019.11.19

View this article at: http://dx.doi.org/10.21037/hbsn.2019.11.19

The introduction of direct-acting antivirals (DAAs) has revolutionized the natural history of chronic hepatitis $\mathrm{C}$ virus (HCV) infection, as the high rates of sustained virologic response (SVR) have been associated with improved survival in both cirrhotic and noncirrhotic patients (1). However, the risk of hepatocellular carcinoma (HCC) after DAA treatment has been a hot topic in the literature of the last few years, especially after two initial studies reporting unexpectedly high rates of both HCC occurrence and recurrence after SVR $(2,3)$.

While several large and prospective studies have subsequently shown that the risk of HCC de novo development is markedly reduced after SVR by DAAs $(1,4)$, the risk of HCC recurrence and the eventual benefit of the antiviral therapy after HCC treatment remains a controversial topic.

The two recent papers by Singal et al. undoubtedly provide advancement in the understanding of the relationship between HCC recurrence and DAA treatment $(5,6)$. In a large multicenter cohort study of almost 800 patients with a history of HCC, the authors demonstrated that the risk of overall and early HCC recurrence was not increased in $\mathrm{HCV}$ patients receiving interferon-free treatment (5). More importantly, the same group showed subsequently that DAA therapy after complete response to HCC therapy was associated with a $46 \%$ reduction in overall mortality, confirming that these patients should be considered for treatment (6).
Given the retrospective nature of the study, several limits should be mentioned. Firstly, the benefit of DAA treatment on survival did not reach significance on sensitivity analysis, probably due to the sample size. Moreover, the authors did not consider some important confounding factors, such as co-morbidities, i.e. diabetes, and more importantly, they did not balance for any portal hypertension-related variables, such as a history of decompensation or presence of varices. However, we believe that the main conclusion of this paper is in line with other large European, American and Asian cohort studies $(7,8)$, all clearly showing that treating HCV infection with DAAs after curative treatment of HCC is associated with increased survival. While the benefit of $\mathrm{HCV}$ eradication in this group of patients seems to be settled, the right timing of DAA therapy initiation appears to be less precise. A recent meta-analysis showed that the presence of active HCC was associated with a high risk of treatment failure (9). Current guidelines do not offer clear indications and, therefore, as shown by a recent study, the attitudes among hepatologist regarding the use and timing of DAA therapy in patients with a history of HCC are very heterogeneous (10). We believe that future studies should address the best interval between HCC curative treatment and DAA therapy.

Another clinical need would be to improve the identification of HCC recurrence predictors after achieving SVR. Some authors have proposed several non-invasive methods to predict the recurrence of HCC in the context of 
$\mathrm{HCV}(11,12)$. The identification of these patients, as shown by Singal et al. (6), appears to be a key point due to the loss of the benefit of DAA therapy on their survival.

Finally, the authors did not dispose of data relative to the development of decompensation during followup, and therefore could not demonstrate an association between the improvement in portal hypertension and the observed survival benefit of DAA therapy in HCC patients. Although this association was shown in the paper by Cabibbo et al. (7), it brings to light a more complex issue: the lack of evidence regarding the impact of DAA treatment on portal hypertension and its complications (1). Indeed, it has been shown that the hepatic venous pressure gradient (HVPG) (13) and its surrogates (14) improve after SVR achievement; however, the effect of DAA therapy on the incidence of clinical outcomes, such as hepatic decompensation, is still controversial. Some initial studies have reported a reduced risk of decompensation after SVR (15), but the most extensive prospective study to date failed to demonstrate a benefit of DAA therapy on the progression to decompensated cirrhosis after SVR (4). As for patients with decompensated cirrhosis, little data is available, because these patients were rarely treated with interferon-based regimens and no studies are available in the DAAs era. However, the significant decrease in patients with HCV-related decompensated cirrhosis on the liver transplant waiting list might suggest a benefit of DAA treatment in this category of patients. We believe that, just as for HCC occurrence and recurrence, compensated and decompensated cirrhosis should be considered as two distinct stages of liver disease, and, therefore, future studies should address the impact of DAA therapy on hepatic decompensation and overall survival separately in these two groups. Similarly, predictors of decompensation should be investigated, in order to identify subjects at higher risk of complications and to provide a tailored follow-up for each patient. Recently, Mandorfer et al. (13) showed that an HVPG reduction $>10 \%$ after SVR was protective against decompensation. Whether non-invasive surrogates of HVPG, such as liver and spleen stiffness, can accurately stratify for the risk of portal hypertension-related complications after DAA therapy, has yet to be determined.

To sum up, over one hundred studies, with large and multicenter cohorts, have been published over the incidence of HCC after DAA therapy; yet, very little evidence is available on the risk of hepatic decompensation after antiviral treatment, even though this event seems to be the main driver of death in patients achieving SVR (16). Whether this publication bias reflects the fact that HCC risk after DAA treatment is an "inflated" argument and more appealing citation-wise after the initial controversy, or it is part of publication strategies using the same cohort for multiple publications, it is unclear. What should be clear is that studies evaluating the incidence of decompensated cirrhosis or further decompensation after SVR achievement, as well the predictors of such events, are urgently needed, because they are crucial for the management and follow-up of cirrhotic patients receiving DAA therapy.

In conclusion, viral eradication should be encouraged in $\mathrm{HCV}$ patients after complete response to HCC treatment, as is it associated with an improvement in overall survival. Future studies should focus on the timing of the treatment initiation and the impact of co-morbidities and portal hypertension severity on the prognosis of patients cured of $\mathrm{HCV}$ infection.

\section{Acknowledgments}

Funding: None.

\section{Footnote}

Conflicts of Interest: All authors have completed the ICMJE uniform disclosure form (available at http://dx.doi. org/10.21037/hbsn.2019.11.19). The authors have no conflicts of interest to declare.

Ethical Statement: The authors are accountable for all aspects of the work in ensuring that questions related to the accuracy or integrity of any part of the work are appropriately investigated and resolved.

Open Access Statement: This is an Open Access article distributed in accordance with the Creative Commons Attribution-NonCommercial-NoDerivs 4.0 International License (CC BY-NC-ND 4.0), which permits the noncommercial replication and distribution of the article with the strict proviso that no changes or edits are made and the original work is properly cited (including links to both the formal publication through the relevant DOI and the license). See: https://creativecommons.org/licenses/by-nc$\mathrm{nd} / 4.0 \%$. 


\section{References}

1. Ioannou GN, Feld JJ. What Are the Benefits of a Sustained Virologic Response to Direct-Acting Antiviral Therapy for Hepatitis C Virus Infection? Gastroenterology 2019;156:446-60.e2.

2. Conti F, Buonfiglioli F, Scuteri A, et al. Early occurrence and recurrence of hepatocellular carcinoma in HCVrelated cirrhosis treated with direct-acting antivirals. J Hepatol 2016;65:727-33.

3. Reig M, Mariño Z, Perelló C, et al. Unexpected high rate of early tumor recurrence in patients with $\mathrm{HCV}$-related HCC undergoing interferon-free therapy. J Hepatol 2016;65:719-26.

4. Carrat F, Fontaine H, Dorival C, et al. Clinical outcomes in patients with chronic hepatitis $\mathrm{C}$ after direct-acting antiviral treatment: a prospective cohort study. Lancet 2019;393:1453-64.

5. Singal AG, Rich NE, Mehta N, et al. Direct-Acting Antiviral Therapy Not Associated With Recurrence of Hepatocellular Carcinoma in a Multicenter North American Cohort Study. Gastroenterology 2019;156:1683-92.e1.

6. Singal AG, Rich NE, Mehta N, et al. Direct-Acting Antiviral Therapy for Hepatitis C Virus Infection Is Associated With Increased Survival in Patients With a History of Hepatocellular Carcinoma. Gastroenterology 2019;157:1253-63.e2.

7. Cabibbo G, Celsa C, Calvaruso V, et al. Direct-acting antivirals after successful treatment of early hepatocellular carcinoma improve survival in $\mathrm{HCV}$-cirrhotic patients. J Hepatol 2019;71:265-73.

8. Dang H, Yeo YH, Yasuda S, et al. Cure with Interferon Free DAA is Associated with Increased Survival in Patients with HCV related HCC from both East and West.

Cite this article as: Dajti E, Ravaioli F, Festi D, Colecchia A. Clinical outcomes after treatment with direct-acting antivirals: not all concern hepatocellular carcinoma risk. HepatoBiliary Surg Nutr 2020;9(4):505-507. doi: 10.21037/hbsn.2019.11.19
Hepatology 2020;71:1910-22.

9. Ji F, Yeo YH, Wei MT, et al. Sustained virologic response to direct-acting antiviral therapy in patients with chronic hepatitis $\mathrm{C}$ and hepatocellular carcinoma: A systematic review and meta-analysis. J Hepatol 2019;71:473-85.

10. Rich NE, Yang JD, Perumalswami PV, et al. Provider Attitudes and Practice Patterns for Direct-Acting Antiviral Therapy for Patients With Hepatocellular Carcinoma. Clin Gastroenterol Hepatol 2020;18:974-83.

11. Ravaioli F, Conti F, Brillanti S, et al. Hepatocellular carcinoma risk assessment by the measurement of liver stiffness variations in $\mathrm{HCV}$ cirrhotics treated with direct acting antivirals. Dig Liver Dis 2018;50:573-9.

12. Casadei Gardini A, Foschi FG, Conti F, et al. Immune inflammation indicators and ALBI score to predict liver cancer in $\mathrm{HCV}$-patients treated with direct-acting antivirals. Dig Liver Dis 2019;51:681-8.

13. Mandorfer M, Kozbial K, Schwabl P, et al. Changes in Hepatic Venous Pressure Gradient Predict Hepatic Decompensation in Patients Who Achieved Sustained Virologic Response to Interferon-Free Therapy. Hepatology 2020;71:1023-36.

14. Ravaioli F, Colecchia A, Dajti E, et al. Spleen stiffness mirrors changes in portal hypertension after successful interferon-free therapy in chronic-hepatitis $\mathrm{C}$ virus patients. World J Hepatol 2018;10:731-42.

15. Nahon P, Layese R, Bourcier V, et al. Incidence of Hepatocellular Carcinoma After Direct Antiviral Therapy for HCV in Patients With Cirrhosis Included in Surveillance Programs. Gastroenterology 2018;155:1436-50.e6.

16. Cabibbo G, Petta S, Barbara M, et al. Hepatic decompensation is the major driver of death in HCVinfected cirrhotic patients with successfully treated early hepatocellular carcinoma. J Hepatol 2017;67:65-71. 